Supporting Information

\title{
Thermodynamic Margin in Carbon Network Modulated Activity Control of Oxygen Reduction Reaction Iron Catalyst
}

\author{
Heesun Park ${ }^{1,2}$, Jiwon $\mathrm{Yu}^{1,3}$, Hyung-Kyu Lim*,4, Sangheon Lee*,1,2 \\ ${ }^{1}$ Department of Chemical Engineering and Materials Science, Ewha Womans University, \\ 52, Ewhayeodae-gil, Seodaemun-gu, Seoul 03760, Republic of Korea \\ ${ }^{2}$ System Health \& Engineering Major in Graduate School (BK21 Plus Program), Ewha Womans \\ University, 52, Ewhayeodae-gil, Seodaemun-gu, Seoul 03760, Republic of Korea \\ ${ }^{3}$ McKetta Department of Chemical Engineering, The University of Texas at Austin, \\ 200 East Dean Keeton Street, Austin, Texas 78712, USA \\ ${ }^{4}$ Division of Chemical Engineering and Bioengineering, Kangwon National University, Chuncheon, \\ Gangwon-do 24341, Republic of Korea
}

Corresponding Authors:

*H.-K.L.: e-mail, hklim@kangwon.ac.kr; tel, +82-33-250-6339; fax, +82-33-259-5551

*S.L.: e-mail, sang@ewha.ac.kr; tel, +82-2-3277-4055; fax, +82-2-3277-3535 


\section{- ORR Pathways}

As summarized below in Eq. 1 to 5, the associative pathway is a common four-electron oxygen reduction reaction (ORR) pathway for a single-atom $\mathrm{FeN}_{4}$ active site, where dissociation of the $\mathrm{OO}$ bond in $\mathrm{O}_{2}$ proceeds through an electrochemical reaction. The adsorption of $\mathrm{O}_{2}$ on the Fe active site (denoted as $*$ ) is the onset of the ORR (Eq. 1). The adsorbed $\mathrm{O}_{2}\left({ }^{*} \mathrm{O}_{2}\right)$ is hydrogenated by the first proton coupled electron transfer (PCET) step (Eq. 2) and becomes *OOH. Then, the $* \mathrm{OOH}$ is converted to $\mathrm{H}_{2} \mathrm{O}$ by the second PCET step (Eq. 3), leaving *O on the Fe active site. Finally, ${ }^{*} \mathrm{O}$ is converted to $* \mathrm{OH}$ and $\mathrm{H}_{2} \mathrm{O}$ by two consecutive PCET steps (Eq. 3 and 4) in series, returning the Fe active site to its original state. The ORR limiting potential is determined by the least favorable reaction energy of the four PCET steps.

$$
\begin{aligned}
& *(\mathrm{aq})+\mathrm{O}_{2}(\mathrm{~g}) \rightarrow * \mathrm{O}_{2}(\mathrm{aq}) \\
& * \mathrm{O}_{2}(\mathrm{aq})+\left[\mathrm{H}^{+}+\mathrm{e}^{-}\right] \rightarrow * \mathrm{OOH}(\mathrm{aq}) \\
& * \mathrm{OOH}(\mathrm{aq})+\left[\mathrm{H}^{+}+\mathrm{e}^{-}\right] \rightarrow * \mathrm{O}(\mathrm{aq})+\mathrm{H}_{2} \mathrm{O}(\mathrm{aq}) \\
& * \mathrm{O}(\mathrm{aq})+\left[\mathrm{H}^{+}+\mathrm{e}^{-}\right] \rightarrow * \mathrm{OH}(\mathrm{aq}) \\
& * \mathrm{OH}(\mathrm{aq})+\left[\mathrm{H}^{+}+\mathrm{e}^{-}\right] \rightarrow *(\mathrm{aq})+\mathrm{H}_{2} \mathrm{O}(\mathrm{aq})
\end{aligned}
$$

The dissociative pathway is another well-known four-electron ORR pathway. For the dissociative pathway, ${ }^{*} \mathrm{OOH}$ produced by the first PCET step is converted to *O- $\mathrm{O}^{*} \mathrm{OH}$ through chemical dissociation of the $\mathrm{OO}$ bond (Eq. 2.5), where ** denotes the carbon site adjacent to the nitrogen atom. Multiple ** sites are available for a given FeNC model; we selected the one with the lowest energy. The *O-**OH is converted to $* \mathrm{OH}_{-}^{* *} \mathrm{OH}$ by the second PCET step (Eq. ${ }^{\prime}$ ), and ${ }^{*} \mathrm{OH}$ in the $* \mathrm{OH}-* * \mathrm{OH}$ is further reduced by the third PCET step to generate $\mathrm{H}_{2} \mathrm{O}$ and leaving *_**OH (Eq. 4'). After the third PCET step, the migration of $\mathrm{OH}$ from the ** site to the * site occurs, returning to the $* \mathrm{OH}$, the product state of third PCET step from the associative pathway. Finally, the * $\mathrm{OH}$ is further reduced by the fourth PCET step to produce $\mathrm{H}_{2} \mathrm{O}$, similar to the associative pathway.

$$
\begin{aligned}
& * \mathrm{OOH}(\mathrm{aq}) \rightarrow * \mathrm{O}_{-} * * \mathrm{OH}(\mathrm{aq}) \\
& * \mathrm{O}-* * \mathrm{OH}(\mathrm{aq})+\left[\mathrm{H}^{+}+\mathrm{e}^{-}\right] \rightarrow * \mathrm{OH}_{-} * * \mathrm{OH}(\mathrm{aq}) \\
& * \mathrm{OH}-* * \mathrm{OH}(\mathrm{aq})+\left[\mathrm{H}^{+}+\mathrm{e}^{-}\right] \rightarrow * *_{-} * \mathrm{OH}(\mathrm{aq})+\mathrm{H}_{2} \mathrm{O}(\mathrm{aq}) \\
& *-* * \mathrm{OH}(\mathrm{aq}) \rightarrow * \mathrm{OH}(\mathrm{aq})
\end{aligned}
$$




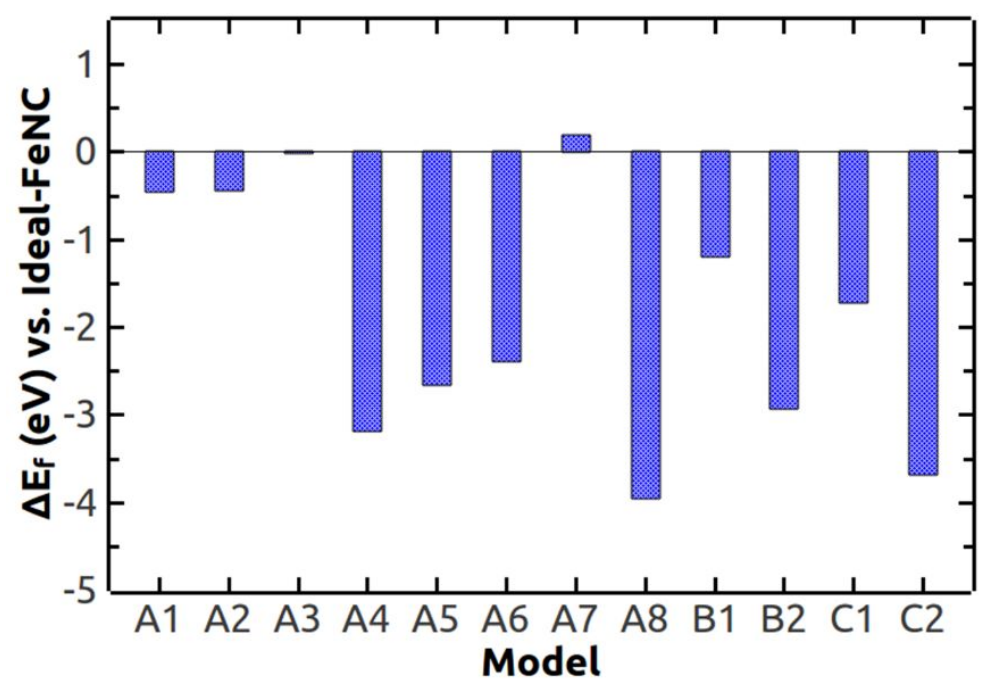

Figure S1. Formation energy of each defective-FeNC model relative to the ideal-FeNC model.

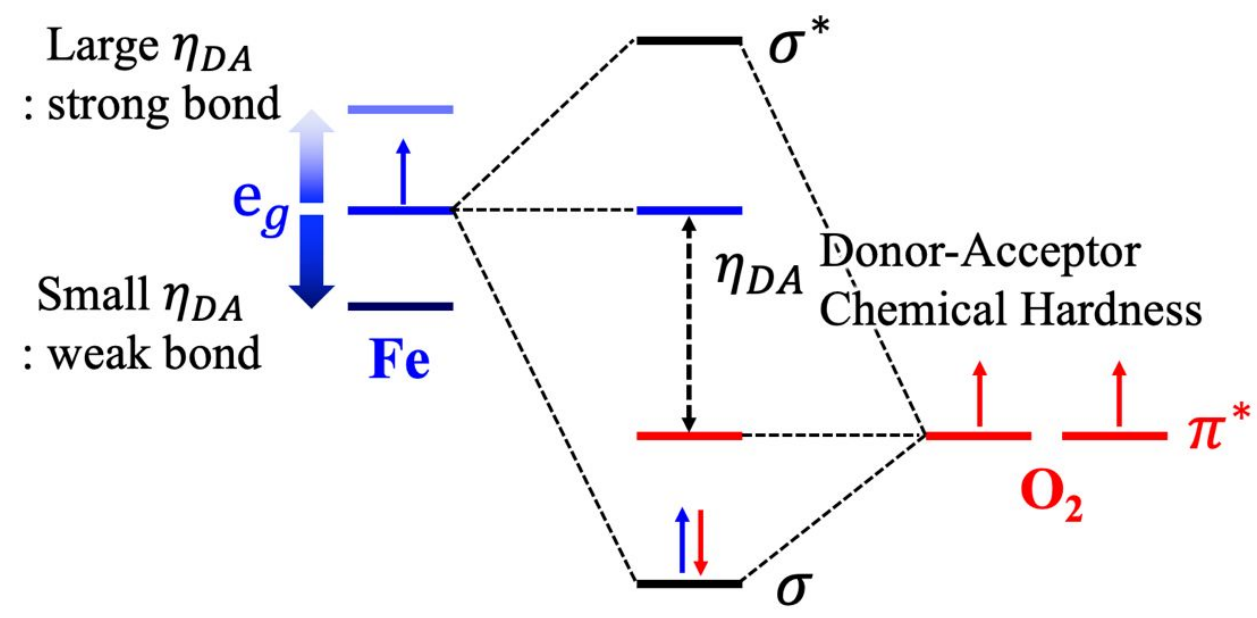

Figure S2. Schematic description of the donor-acceptor chemical hardness concept related to the strength of $\mathrm{Fe}-\mathrm{O}_{2}$ bonding. 


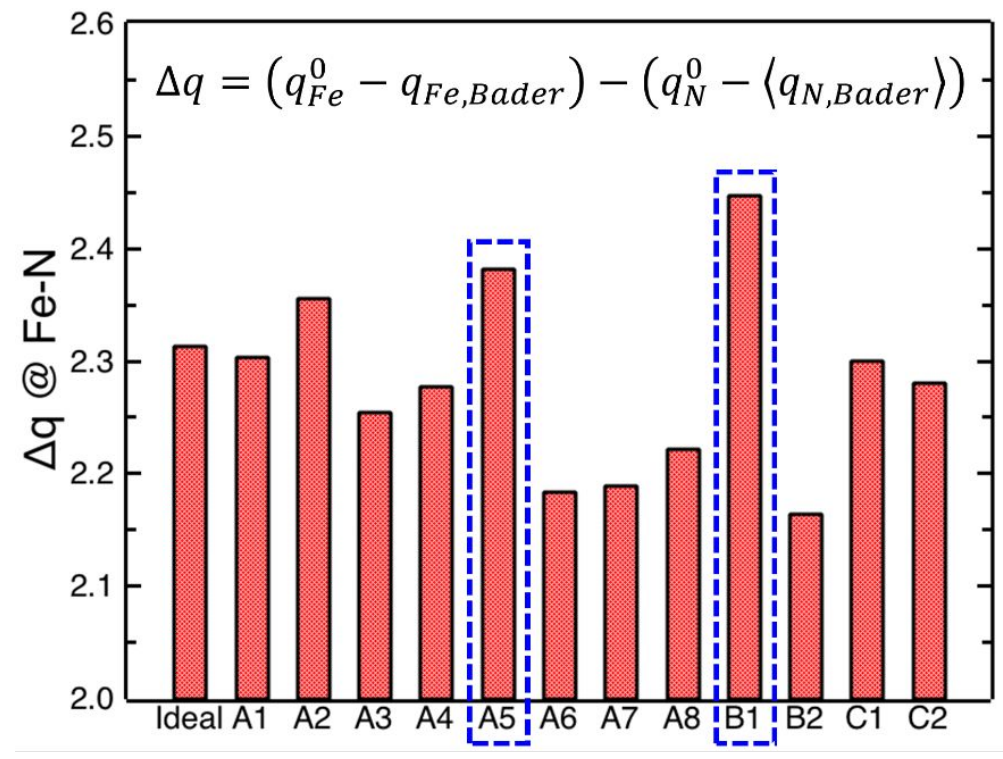

\section{Strong dipole-dipole interaction between *O-H and $\mathrm{Fe}-\mathrm{N}$ bonds} (a) A5 \& B1

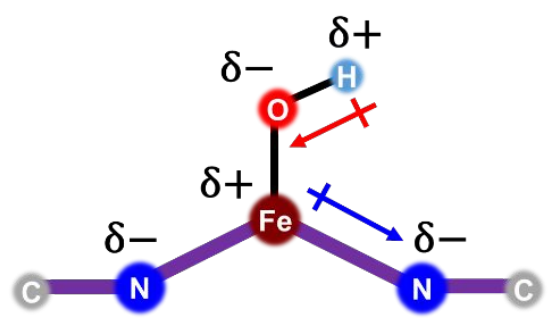

Model

Figure S3. Differential partial charge at Fe-N bonds based on the Bader charge analysis and the schematic of dipole-dipole interaction occurs in * $\mathrm{OH}$ structure. The reference charges of $\mathrm{Fe}\left(q_{\mathrm{Fe}}^{0}\right)$ and $\mathrm{N}$ $\left(q_{N}^{0}\right)$ are 8 and 5 , respectively. The Bader partial charge of nitrogen is averaged out for four nitrogen atoms bonded with $\mathrm{Fe}$. 


\section{$\underline{1 \text { st } \text { PCET }}$}

$$
\begin{aligned}
& \mathrm{O}_{2}(\mathrm{~g})+\left[\mathrm{H}^{+}+\mathrm{e}^{-}\right] \stackrel{\Delta \mathbf{G}_{\mathbf{l}}}{\longrightarrow} \cdot \mathrm{OOH}(\mathrm{g})
\end{aligned}
$$

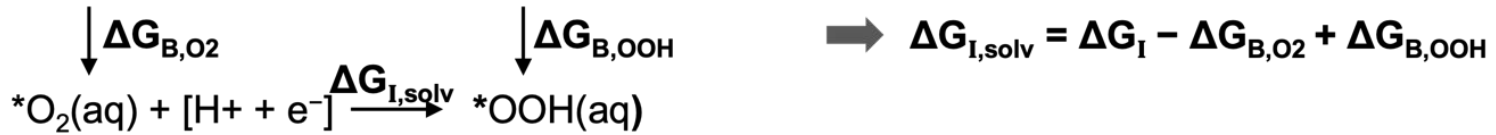

\section{$2^{\text {nd }}$ PCET}

$$
\begin{aligned}
& \cdot \mathrm{OOH}(\mathrm{g})+\left[\mathrm{H}^{+}+\mathrm{e}^{-}\right] \stackrel{\Delta \mathbf{G}_{\mathrm{II}}}{\longrightarrow} \cdot \mathrm{O}(\mathrm{g})+\mathrm{H}_{2} \mathrm{O}(\mathrm{g}) \\
& \downarrow \Delta G_{\mathrm{B}, \mathrm{OOH}} \quad \downarrow \Delta \mathrm{G}_{\mathrm{B}, \mathrm{O}} \mid \Delta \mathrm{G}_{\mathrm{H} 2 \mathrm{O}, \text { solv }} \Rightarrow \Delta \mathrm{G}_{\mathrm{II}, \mathrm{solv}}=\Delta \mathrm{G}_{\mathrm{II}}-\Delta \mathrm{G}_{\mathrm{B}, \mathrm{OOH}}+\Delta \mathrm{G}_{\mathrm{B}, \mathrm{O}}
\end{aligned}
$$

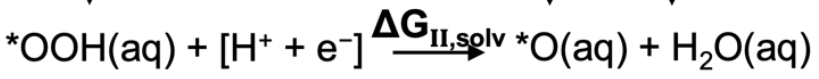

$$
\begin{aligned}
& +\Delta G_{\mathrm{H} 2 \mathrm{O}, \mathrm{solv}}
\end{aligned}
$$

\section{$3^{\text {rd }}$ PCET}

$$
\begin{aligned}
& \cdot \mathrm{O}(\mathrm{g})+\left[\mathrm{H}^{+}+\mathrm{e}^{-}\right] \stackrel{\Delta \mathrm{G}_{\mathrm{IU}}}{\longrightarrow} \cdot \mathrm{OH}(\mathrm{g})
\end{aligned}
$$

\begin{tabular}{|c|c|c|}
\hline & $\mathrm{G}_{\mathrm{B}, \mathrm{OOH}}=1.20 \times \Delta G$ & $\Delta G_{I \text {, solv }}=0$ \\
\hline$\Delta G_{I I}=0.80$ & $\Delta G_{B, 0}=1.13 \times \Delta G_{B, 02}-3.91$ & $\Delta G_{\text {II,solv }}=-0.07 \times \Delta G_{B, 02}-2.50$ \\
\hline$\Delta G_{\text {III }}=-2.67$ & Linear scaling relationship & $\Delta G_{\mathrm{III}, \text { solv }}=-1.13 \times \Delta G_{\mathrm{B}, \mathrm{O} 2}+\Delta \mathrm{G}_{\mathrm{B}, \mathrm{OH}}+1.24$ \\
\hline$\Delta G_{I V}=-2.79$ & & $\mathrm{~B}_{\mathrm{B}, \mathrm{OH}}-3.05$ \\
\hline $\begin{array}{l}\text { Gas-phase } \\
\text { molecular } \\
\text { DFT energy }\end{array}$ & $\begin{array}{c}\Delta \mathbf{G}_{\mathrm{H} 2 \mathrm{O}, \text { solv }}=-0.26 \\
\text { Hydration free energy } \\
\text { of } \mathrm{H}_{2} \mathrm{O} \text { molecule }\end{array}$ & $\begin{array}{l}U_{L}(V \text { vs. CHE })= \\
-\operatorname{MAX}\left(\Delta G_{\mathrm{I}, \text { solv }}, \Delta G_{\mathrm{II}, \text { solv }}, \Delta G_{\mathrm{III}, \text { solv }}\right.\end{array}$ \\
\hline
\end{tabular}

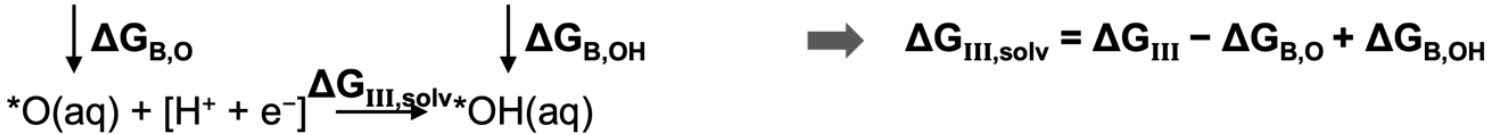

\section{$4^{\text {th }}$ PCET}

$$
\begin{aligned}
& \cdot \mathrm{OH}(\mathrm{g})+\left[\mathrm{H}^{+}+\mathrm{e}^{-}\right] \stackrel{\Delta \mathrm{G}_{\mathrm{IV}}}{\longrightarrow} \mathrm{H}_{2} \mathrm{O}(\mathrm{g}) \\
& \downarrow \Delta \mathbf{G}_{\mathrm{B}, \mathrm{OH}} \quad \downarrow \Delta \mathbf{G}_{\mathrm{H} 2 \mathrm{O} \text {,solv }} \Rightarrow \Delta \mathrm{G}_{\mathrm{IV}, \text { solv }}=\Delta \mathrm{G}_{\mathrm{IV}}-\Delta \mathrm{G}_{\mathrm{B}, \mathrm{OH}}+\Delta \mathrm{G}_{\mathrm{H} 2 \mathrm{O}, \text { solv }} \\
& { }^{*} \mathrm{OH}(\mathrm{aq})+\left[\mathrm{H}^{+}+\mathrm{e}^{-}\right] \stackrel{\Delta \mathbf{G}_{\mathrm{IV}, \text { solv }}}{ } \mathrm{H}_{2} \mathrm{O}(\mathrm{aq})
\end{aligned}
$$

Figure S4. Procedure of descriptor analysis based on the thermodynamic equation for the associative ORR pathway and the linear scaling relationship obtained from our DFT calculation. 


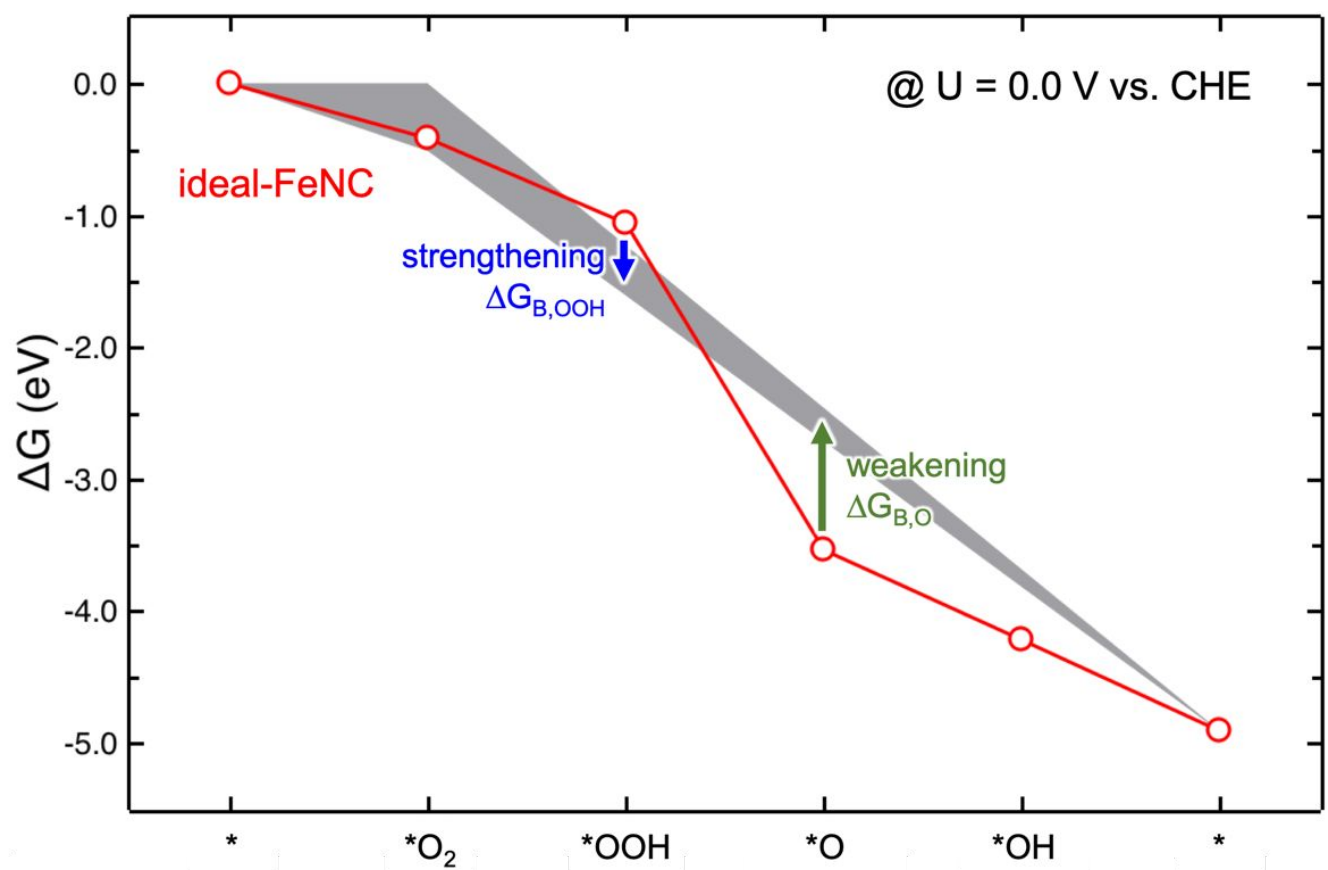

Figure S5. Approaches of binding free energy modulation for *OOH and *O for distributing ORR energy evenly in each PCET step.

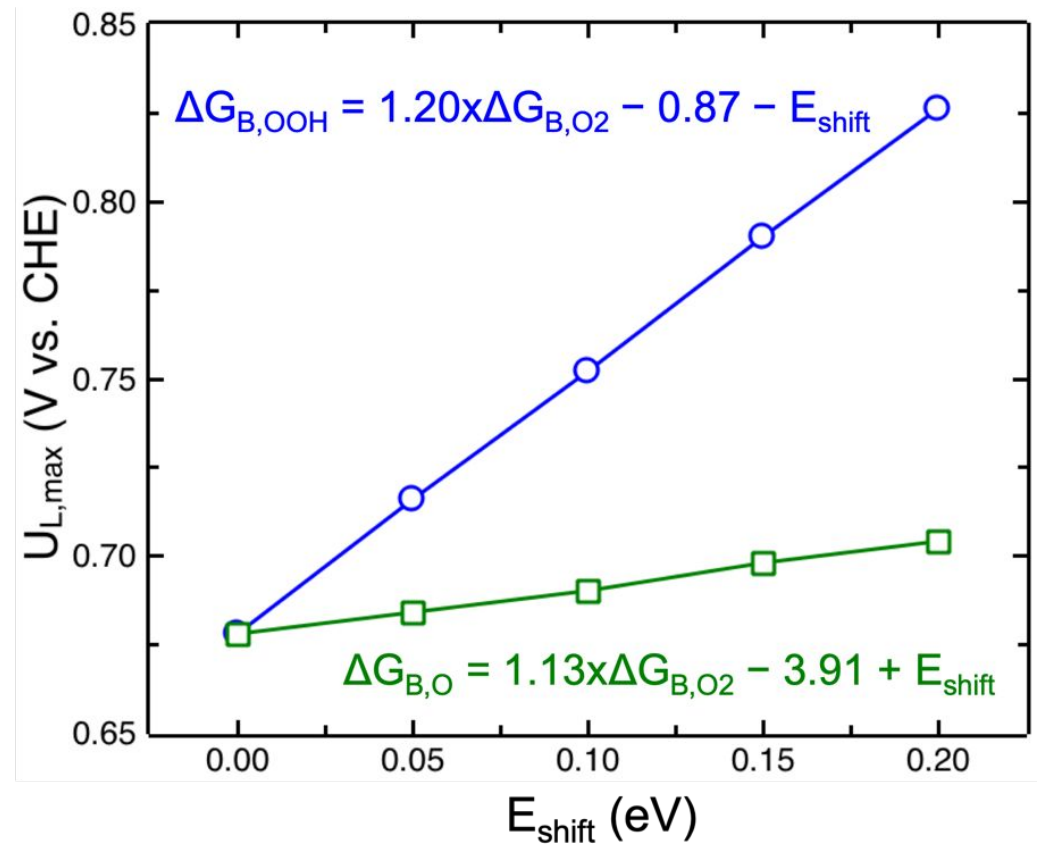

Figure S6. Effect of binding free energy modulation for $* \mathrm{OOH}$ and $* \mathrm{O}$ on the maximum $\mathrm{ORR}$ limiting potential estimated by a two-dimensional $\mathrm{U}_{\mathrm{L}}$ map. 